\title{
Infusional Fluorouracil/Leucovorin Regimen
}

National Cancer Institute

\section{Source}

National Cancer Institute. Infusional Fluorouracil/Leucovorin Regimen. NCI Thesaurus.

Code C136256.

A chemotherapy regimen consisting of infusional fluorouracil and leucovorin that is used for the treatment of colon cancer. 